\title{
Timing of cranioplasty: a 10.75-year single-center analysis of 754 patients
}

\author{
Ryan P. Morton, MD, ${ }^{1}$ Isaac Josh Abecassis, MD, ${ }^{1}$ Josiah F. Hanson, BS, ${ }^{1}$ Jason K. Barber, MS, ${ }^{1}$ \\ Mimi Chen, ${ }^{1}$ Cory M. Kelly, BS, ${ }^{1}$ John D. Nerva, MD, ${ }^{1}$ Samuel N. Emerson, MD, PhD, ${ }^{1}$ \\ Chibawanye I. Ene, MD, PhD, ${ }^{1}$ Michael R. Levitt, MD, ${ }^{1-3}$ Michelle M. Chowdhary, MD, ${ }^{1}$ \\ Andrew L. Ko, MD, ${ }^{1}$ and Randall M. Chesnut, MD ${ }^{1}$
}

\begin{abstract}
Departments of ${ }^{1}$ Neurological Surgery, ${ }^{2}$ Radiology, and ${ }^{3}$ Mechanical Engineering, University of Washington School of Medicine, Seattle, Washington
\end{abstract}

OBJECTIVE Despite their technical simplicity, cranioplasty procedures carry high reported morbidity rates. The authors here present the largest study to date on complications after cranioplasty, focusing specifically on the relationship between complications and timing of the operation.

METHODS The authors retrospectively reviewed all cranioplasty cases performed at Harborview Medical Center over the past 10.75 years. In addition to relevant clinical and demographic characteristics, patient morbidity and mortality data were abstracted from the electronic medical record. Cox proportional-hazards models were used to analyze variables potentially associated with the risk of infection, hydrocephalus, seizure, hematoma, and bone flap resorption.

RESULTS Over the course of 10.75 years, 754 cranioplasties were performed at a single institution. Sixty percent of the patients who underwent these cranioplasties were male, and the median follow-up overall was 233 days. The 30-day mortality rate was $0.26 \%$ (2 cases, both due to postoperative epidural hematoma). Overall, $24.6 \%$ percent of the patients experienced at least 1 complication including infection necessitating explantation of the flap (6.6\%), postoperative hydrocephalus requiring a shunt $(9.0 \%)$, resorption of the flap requiring synthetic cranioplasty $(6.3 \%)$, seizure $(4.1 \%)$, postoperative hematoma requiring evacuation $(2.3 \%)$, and other (1.6\%).

The rate of infection was significantly higher if the cranioplasty had been performed $<14$ days after the initial craniectomy $(p=0.007$, Holm-Bonferroni-adjusted $p=0.028)$. Hydrocephalus was significantly correlated with time to cranioplasty (OR 0.92 per 10-day increase, $p<0.001$ ) and was most common in patients whose cranioplasty had been performed $<90$ days after initial craniectomy. New-onset seizure, however, only occurred in patients who had undergone their cranioplasty $>90$ days after initial craniectomy. Bone flap resorption was the least likely complication for patients whose cranioplasty had been performed between 15 and 30 days after initial craniectomy. Resorption was also correlated with patient age, with a hazard ratio of 0.67 per increase of 10 years of age $(p=0.001)$.

CONCLUSIONS Cranioplasty performed between 15 and 30 days after initial craniectomy may minimize infection, seizure, and bone flap resorption, whereas waiting > 90 days may minimize hydrocephalus but may increase the risk of seizure.

https://thejns.org/doi/abs/10.3171/2016.11.JNS161917

KEY WORDS cranioplasty; timing; infection; resorption; complication; traumatic brain injury

$\mathrm{C}$ RANIOPLASTY aims to treat a cosmetic skull defect with either a stored autologous bone flap or a custom synthetic prosthesis. This relatively simple neurosurgical procedure is associated with complication rates of $15 \%-35 \% .^{1-23}$ In efforts to find the most favorable setting to perform cranioplasty, prior investigations have focused on the timing of cranioplasty after initial craniectomy. Most previous reports, however, have been limited to smaller series or pooled analyses with mixed conclu- sions. In an attempt to clarify the literature, we present the largest study to date on complications after cranioplasty, focusing specifically on the association between complication rates and the timing of the operation.

\section{Methods}

This study was reviewed and approved by the University of Washington's institutional review board. We retro-

ABBREVIATIONS IPH = intraparenchymal hemorrhage; $\mathrm{MCA}=$ middle cerebral artery; $\mathrm{SAH}=$ subarachnoid hemorrhage; $\mathrm{TBI}=$ traumatic brain injury .

SUBMITTED August 22, 2016. ACCEPTED November 21, 2016.

INCLUDE WHEN CITING Published online August 11, 2017; DOI: 10.3171/2016.11.JNS161917. 
spectively reviewed all cranioplasties performed at Harborview Medical Center, an urban, tertiary care, Level I trauma center, over the past 10.75 years. In addition to relevant clinical and demographic data, the following prespecified data points were abstracted from the electronic medical record: indication for initial craniectomy, timing of cranioplasty after initial craniectomy, postoperative cranioplasty infection requiring explantation of the bone flap, postoperative hydrocephalus requiring cerebrospinal fluid diversion, new-onset seizure, postoperative hematoma requiring evacuation, autologous bone flap resorption requiring synthetic cranioplasty, and location of discharge (home, rehabilitation facility, or skilled nursing facility).

Statistical analysis was performed using SPSS software version 19 (IBM Corp.). Cox proportional-hazards models were used to analyze variables potentially associated with the risk of infection, hydrocephalus, seizure, hematoma, and bone resorption. Hazard ratios were calculated, and $\mathrm{p}$ values $<0.01$ were considered significant. Tukey's range test and Holm-Bonferroni corrections were used for post hoc comparisons.

\section{Results}

Over the 10.75 -year study period, 754 cranioplasty procedures were performed. Among the patients who underwent these cranioplasties, 455 were male $(60.3 \%)$ and the mean age was 44 years (range 1-86 years). The median follow-up after cranioplasty was 233 days. Indications for initial craniectomy included traumatic brain injury (TBI; 51.4\%), spontaneous intraparenchymal hemorrhage (IPH; $13.8 \%$ ), aneurysmal subarachnoid hemorrhage (SAH; $13.5 \%$ ), malignant middle cerebral artery (MCA) infarction $(9.7 \%)$, infection after craniotomy $(5.2 \%)$, brain edema after tumor surgery (2.9\%), spontaneous brain abscess (0.7\%), and other (2.8\%; Table 1$)$.

An autologous bone flap was used in 532 cases (70.6\%), whereas a synthetic prosthesis was used in $222(29.4 \%)$. The material used for the synthetic prostheses varied, but polyetheretherketone (PEEK) was the most common.

The 30-day mortality was $0.3 \%$ ( 2 cases), with both deaths resulting from postoperative epidural hematoma. Overall, $24.6 \%$ of patients experienced at least 1 complication including infection necessitating explantation of the flap (6.6\%), postoperative hydrocephalus requiring a shunt $(9.0 \%)$, resorption of the autologous flap requiring synthetic cranioplasty $(6.3 \%)$, seizure $(4.1 \%)$, postoperative hematoma requiring evacuation (2.3\%), and other (1.6\%). Upon discharge, $58.7 \%$ of patients returned home, $13.8 \%$ to a rehabilitation facility, and $27.2 \%$ to a skilled nursing facility or adult family home.

\section{Factors Influencing Complications Infection}

When evaluating the association between postoperative complication rates and timing of the cranioplasty, we found the rate of infection was significantly higher if the cranioplasty had been performed $<14$ days after the initial craniectomy (HR 3.62, $\mathrm{p}=0.007$, Holm-Bonferroni-adjusted $p=0.028$ ). There was no significant difference with any other variable (age, sex, indication for initial craniec-
TABLE 1. Indication for craniectomy in the cranioplasty population at a single institution

\begin{tabular}{lrr}
\hline \multicolumn{1}{c}{ Indication } & $\begin{array}{c}\text { No. of } \\
\text { Patients }\end{array}$ & $\%$ \\
\hline $\begin{array}{l}\text { TBI (depressed skull fracture, extraaxial hematoma, } \\
\text { intraaxial hematoma, \&/or diffuse edema) }\end{array}$ & 388 & 51.4 \\
\hline IPH (spontaneous or AVM) & 104 & 13.8 \\
\hline SAH & 102 & 13.5 \\
\hline Ischemic stroke w/ malignant edema & 73 & 9.7 \\
\hline Postop infection of previous craniotomy & 39 & 5.2 \\
\hline Brain edema after tumor surgery & 22 & 2.9 \\
\hline Spontaneous brain abscess & 5 & 0.7 \\
\hline Other & 21 & 2.8 \\
\hline
\end{tabular}

$\mathrm{AVM}=$ arteriovenous malformation.

tomy, autologous versus synthetic flap, material used for synthetic flap, concomitant shunt placement, and location of discharge). We have previously written in detail about cranioplasty infections regarding the use of synthetic versus autologous flaps. ${ }^{13}$

\section{Hydrocephalus}

Hydrocephalus was significantly correlated with time to cranioplasty (OR 0.92 per 10 -day increase, $\mathrm{p}<0.001$ ) and was most common in patients whose cranioplasty had been performed $<90$ days after initial craniectomy. Additionally, the initial indication for craniectomy significantly influenced the rate of hydrocephalus $(\mathrm{p}=0.004)$, with significant pairwise relationships between SAH (19.6\%), TBI $(6.2 \%, \mathrm{p}<0.01)$, and IPH $(4.8 \%, \mathrm{p}<0.05$; Table 2$)$. Lastly, discharge location was significantly correlated with postoperative hydrocephalus requiring a shunt $(\mathrm{p}=0.007)$, with patients discharged to a skilled nursing or rehabilitation facility reporting the highest rates $(14.4 \%$ and $14.6 \%$, respectively).

\section{Seizure}

The indication for initial craniectomy influenced which

TABLE 2. Indication for initial craniectomy versus postoperative hydrocephalus and seizure

\begin{tabular}{|c|c|c|c|c|}
\hline \multirow[b]{2}{*}{ Indication for Craniectomy } & \multicolumn{2}{|c|}{$\begin{array}{c}\text { Postop } \\
\text { Hydrocephalus }\end{array}$} & \multicolumn{2}{|c|}{$\begin{array}{l}\text { Postop } \\
\text { Seizure }\end{array}$} \\
\hline & $\%$ & $\mathrm{p}$ Value & $\%$ & $\mathrm{p}$ Value \\
\hline TBI & $6.2^{*}$ & 0.004 & 3.1 & $0.040 \dagger$ \\
\hline Ischemic stroke & 11.0 & & 12.3 & \\
\hline $\mathrm{IPH}$ & $4.8 \ddagger$ & & 4.8 & \\
\hline $\mathrm{SAH}$ & $19.6^{*} \ddagger$ & & 2.0 & \\
\hline Brain abscess/empyema & 0.0 & & 0.0 & \\
\hline Brain edema & 18.2 & & 0.0 & \\
\hline Infection from previous craniotomy & 10.3 & & 5.1 & \\
\hline Other & 14.3 & & 4.8 & \\
\hline
\end{tabular}


TABLE 3. Complication rates after cranioplasty in published series

\begin{tabular}{|c|c|c|c|c|c|c|c|c|}
\hline Authors \& Year & Population & $\begin{array}{c}\text { No. of } \\
\text { Patients }\end{array}$ & $\begin{array}{l}\text { Infection } \\
\text { Rate }\end{array}$ & $\begin{array}{c}\text { Hydrocephalus } \\
\text { Rate }\end{array}$ & $\begin{array}{l}\text { Resorption } \\
\text { Rate }\end{array}$ & $\begin{array}{l}\text { Seizure } \\
\text { Rate }\end{array}$ & $\begin{array}{c}\text { Hematoma } \\
\text { Rate }\end{array}$ & $\begin{array}{c}\text { Mortality } \\
\text { Rate }\end{array}$ \\
\hline Walcott et al., 2013 & TBI, stroke & 239 & 12.1 & 5.0 & NR & 3.4 & 3.4 & 0.0 \\
\hline Chang et al., 2010 & SAH, TBI, stroke, tumor, infection, ICH & 212 & 7.1 & NR & NR & NR & 6.1 & 0.5 \\
\hline Chibbaro et al., 2011 & $\mathrm{TBI}$ & 147 & 4.1 & NR & NR & NR & 0.7 & NR \\
\hline De Bonis et al., 2012 & TBI, vascular disease, tumor, elective & 218 & 8.7 & NR & 5.9 & NR & 2.8 & 0.0 \\
\hline Gooch et al., 2009 & TBI, stroke, infection & 62 & 11.3 & 1.6 & 6.5 & 1.6 & 3.2 & NR \\
\hline Sobani et al., 2011 & TBI, stroke, tumor & 96 & 3.1 & 3.1 & 2.1 & 15.6 & 5.2 & NR \\
\hline Stephens et al., 2010 & TBI (combat) & 108 & 12.0 & NR & NR & 7.4 & 7.4 & 0.9 \\
\hline Zanaty et al., 2015 & SAH, TBI, stroke, EDH/SDH & 348 & 26.4 & 13.5 & NR & 14.4 & 6.9 & 3.2 \\
\hline Piedra et al., 2012 & Stroke & 74 & 10.8 & 1.4 & 2.7 & NR & 4.1 & NR \\
\hline Current study & $\begin{array}{l}\text { TBI, stroke, IPH, SAH, infection, tumor, } \\
\text { elective }\end{array}$ & 754 & 6.6 & 9.0 & 6.3 & 4.1 & 2.3 & 0.3 \\
\hline
\end{tabular}

$\mathrm{EDH} / \mathrm{SDH}=$ epidural hematoma/subdural hematoma; $\mathrm{ICH}$ = intracranial hemorrhage; NR = not reported.

patients were more likely to develop a first-time seizure after cranioplasty, with those having malignant MCA infarction being the largest subpopulation (12.3\%; Table 2). However, there were no significant pairwise relationships after applying Tukey post hoc adjustments. Seizures occurred only in patients whose cranioplasty had occurred more than 90 days after initial craniectomy.

\section{Resorption}

When evaluating the 532 cases of autologous cranioplasty, resorption was least likely for patients whose cranioplasty had been performed between 15 and 30 days after initial craniectomy. Resorption was also correlated with patient age, with a hazard ratio of 0.67 per increase of 10 years of age $(p=0.001)$, meaning that younger patients were more likely to experience this phenomenon than older patients. Indication for initial craniectomy did not influence subsequent rates of resorption in our study.

\section{Hematoma}

There was no difference with any other variable on the development of a postoperative hematoma requiring evacuation.

\section{Discussion}

We have presented the largest series of cranioplasties to date, with a focus on the relationship between cranioplasty timing and postoperative complications. Our complication rates compare favorably to those reported previously (Table 3). To date, no large study has attempted to stringently evaluate the association between the timing of cranioplasty after initial craniectomy and the variety of postoperative complications other than infection. One large systematic review failed to find any statistically significant association with infection when comparing "early" $(<3$ months) to "late" cranioplasty. ${ }^{22}$ However, smaller sample sizes limited the statistical power in that review, and the timing of cranioplasty was categorized into either before or after 3 months from initial craniectomy.

The influence of very early ( $<30$ days) or ultra-early
( $<14$ days) cranioplasty in the current study provides additional information and clinical guidance not previously available due to sample size limitation. Our study attempts to address this problem by reporting single-center results for 754 patients. During the study period, cranioplasties were performed at various dates in the postoperative period. Some providers even performed the cranioplasty < 14 days after the decompression. Often in these ultra-early cases, there was a logistical desire by both the physician and the patient's family to replace the flap during the primary hospitalization rather than after discharge. Early cranioplasty was also thought to aid in patient mobilization. Our data suggest, however, that performing a cranioplasty in the ultra-early period increases the risk of infection. Waiting to perform the procedure between 15 and 90 days after initial craniectomy is least likely to result in most categories of complications, with the period between 15 and 30 days postcraniectomy being ideal as it helps to minimize infection, seizure, and resorption while still being a relatively short time window after the initial craniectomy to minimize the time that the patient will spend without a bone flap in place and in a helmet. Waiting > 90 days may minimize the risk of hydrocephalus but may also increase the risk of seizure (Fig. 1).

This study has several limitations. First, while the sample size is large, it is still a single-center study. However, the consecutive nature of our review suggests that the proportion of etiology of initial craniectomy is probably representative of the overall cranioplasty population. Additionally, the study's retrospective nature obviates a proper control group. Prospective studies could further validate our findings. Lastly, the correlation between hydrocephalus and cranioplasty may result from preexisting hydrocephalus not clinically apparent until after cranioplasty placement.

\section{Conclusions}

Timing of cranioplasty is related to postoperative complication rates. Infection risk is highest within 14 days of initial craniectomy, hydrocephalus risk is highest within 90 days, and seizure risk is highest after 90 days. Cra- 


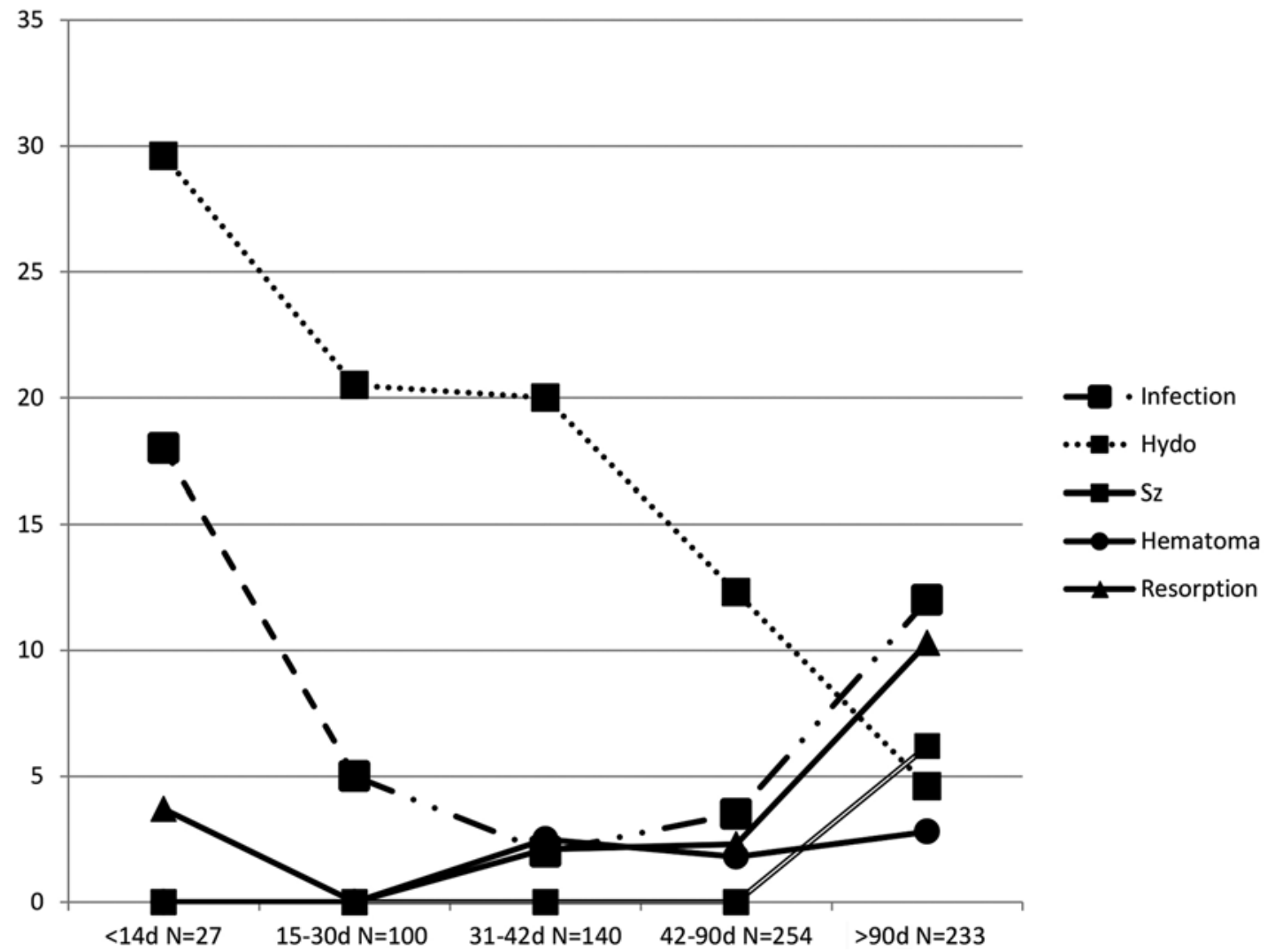

FIG. 1. Complication rate of cranioplasty versus timing of surgery. $d$ = days; Hydo = hydrocephalus; $S z=$ seizure.

nioplasty between 15 and 30 days minimizes the risk of infection, seizure, and autologous flap resorption while still minimizing the time the patient will spend without a bone flap.

\section{References}

1. Chang V, Hartzfeld P, Langlois M, Mahmood A, Seyfried D: Outcomes of cranial repair after craniectomy. J Neurosurg 112:1120-1124, 2010

2. Chibbaro S, Di Rocco F, Mirone G, Fricia M, Makiese O, Di Emidio P, et al: Decompressive craniectomy and early cranioplasty for the management of severe head injury: a prospective multicenter study on 147 patients. World Neurosurg 75:558-562, 2011

3. De Bonis P, Frassanito P, Mangiola A, Nucci CG, Anile C, Pompucci A: Cranial repair: how complicated is filling a "hole"? J Neurotrauma 29:1071-1076, 2012

4. Gooch MR, Gin GE, Kenning TJ, German JW: Complications of cranioplasty following decompressive craniectomy: analysis of 62 cases. Neurosurg Focus 26(6):E9, 2009

5. Grossman N, Shemesh-Jan HS, Merkin V, Gideon M, Cohen A: Deep-freeze preservation of cranial bones for future cranioplasty: nine years of experience in Soroka University Medical Center. Cell Tissue Bank 8:243-246, 2007

6. Iwama T, Yamada J, Imai S, Shinoda J, Funakoshi T, Sakai $\mathrm{N}$ : The use of frozen autogenous bone flaps in delayed cranioplasty revisited. Neurosurgery 52:595-596, 2003

7. Jho DH, Neckrysh S, Hardman J, Charbel FT, Amin-Hanjani $\mathrm{S}$ : Ethylene oxide gas sterilization: a simple technique for storing explanted skull bone. Technical note. J Neurosurg 107:440-445, 2007

8. Kriegel RJ, Schaller C, Clusmann H: Cranioplasty for large skull defects with PMMA (polymethylmethacrylate) or Tutoplast processed autogenic bone grafts. Zentralbl Neurochir 68:182-189, 2007

9. Liang W, Xiaofeng Y, Weiguo L, Gang S, Xuesheng Z, Fei C, et al: Cranioplasty of large cranial defect at an early stage after decompressive craniectomy performed for severe head trauma. J Craniofac Surg 18:526-532, 2007

10. Liao CC, Kao MC: Cranioplasty for patients with severe depressed skull bone defect after cerebrospinal fluid shunting. J Clin Neurosci 9:553-555, 2002

11. Lu Y, Hui G, Liu F, Wang Z, Tang Y, Gao S: Survival and regeneration of deep-freeze preserved autologous cranial bones after cranioplasty. Br J Neurosurg 26:216-221, 2012

12. Morina A, Kelmendi F, Morina Q, Dragusha S, Ahmeti F, Morina D, et al: Cranioplasty with subcutaneously preserved autologous bone grafts in abdominal wall-experience with 75 cases in a post-war country Kosova. Surg Neurol Int 2:72, 2011

13. Morton RP, Abecassis IJ, Hanson JF, Barber J, Nerva JD, Emerson SN, et al: Predictors of infection after 754 cranioplasty operations and the value of intraoperative cultures for cryopreserved bone flaps. J Neurosurg 125:766-770, 2016

14. Movassaghi K, Ver Halen J, Ganchi P, Amin-Hanjani S, Mesa J, Yaremchuk MJ: Cranioplasty with subcutaneously preserved autologous bone grafts. Plast Reconstr Surg 117:202-206, 2006

15. Piedra MP, Thompson EM, Selden NR, Ragel BT, Guillaume DJ: Optimal timing of autologous cranioplasty after decompressive craniectomy in children. J Neurosurg Pediatr 10:268-272, 2012

16. Sobani ZA, Shamim MS, Zafar SN, Qadeer M, Bilal N, Murtaza SG, et al: Cranioplasty after decompressive craniectomy: An institutional audit and analysis of factors related to complications. Surg Neurol Int 2:123, 2011 
17. Staffa G, Nataloni A, Compagnone C, Servadei F: Custom made cranioplasty prostheses in porous hydroxy-apatite using 3D design techniques: 7 years experience in 25 patients. Acta Neurochir (Wien) 149:161-170, 2007

18. Stephens FL, Mossop CM, Bell RS, Tigno T Jr, Rosner MK, Kumar A, et al: Cranioplasty complications following wartime decompressive craniectomy. Neurosurg Focus 28(5):E3, 2010

19. Walcott BP, Kwon CS, Sheth SA, Fehnel CR, Koffie RM, Asaad WF, et al: Predictors of cranioplasty complications in stroke and trauma patients. J Neurosurg 118:757-762, 2013

20. Wiggins A, Austerberry R, Morrison D, Ho KM, Honeybul $\mathrm{S}$ : Cranioplasty with custom-made titanium plates -14 years experience. Neurosurgery 72:248-256, 2013

21. Wurm G, Tomancok B, Holl K, Trenkler J: Prospective study on cranioplasty with individual carbon fiber reinforced polymer (CFRP) implants produced by means of stereolithography. Surg Neurol 62:510-521, 2004

22. Yadla S, Campbell PG, Chitale R, Maltenfort MG, Jabbour P, Sharan AD: Effect of early surgery, material, and method of flap preservation on cranioplasty infections: a systematic review. Neurosurgery 68:1124-1130, 2011

23. Zanaty M, Chalouhi N, Starke RM, Clark SW, Bovenzi CD, Saigh M, et al: Complications following cranioplasty: incidence and predictors in 348 cases. J Neurosurg 123:182188,2015

\section{Disclosures}

The authors report no conflict of interest concerning the materials or methods used in this study or the findings specified in this paper.

\section{Author Contributions}

Conception and design: Abecassis, Barber, Levitt, Chowdhary, Ko, Chesnut. Acquisition of data: Morton, Abecassis, Hanson, Chen, Nerva, Emerson, Ene. Analysis and interpretation of data: Abecassis, Levitt, Chowdhary, Ko, Chesnut. Drafting the article: Abecassis. Critically revising the article: Abecassis, Kelly, Levitt, Ko, Chesnut. Statistical analysis: Barber. Study supervision: Abecassis.

\section{Supplemental Information \\ Previous Presentations}

Portions of this research were presented orally at the Annual Scientific Meeting of the American Association of Neurological Surgeons held in Chicago, Illinois, in April 2016.

\section{Correspondence}

Ryan P. Morton, c/o Neuroscience Publications, University of Washington, Box 359924, 325 9th Ave., Seattle, WA 98104. email: publications@neurosurgery.washington.edu. 